\title{
Baclofen overdose from possible intrinsic malfunction of SynchroMed II pump
}

\author{
Justin R. Davanzo, MD, and Elias Rizk, MD \\ Department of Neurosurgery, Penn State Hershey Medical Center, Hershey, Pennsylvania
}

This is a case report illustrating an overdose of baclofen in a 10 -year-old boy due to a likely malfunction of a SynchroMed II pump. This ultimately necessitated a pump replacement. One-year follow-up showed no further incidents of baclofen overdose, with multiple pump refills.

http://thejns.org/doi/abs/10.3171/2015.1.PEDS14500

KEY WORDS baclofen; pump; overdose; functional neurosurgery

$\mathrm{T}$ HE use of intrathecal baclofen as an effective therapy for spasticity was first described in 1984 by Penn and Kroin. ${ }^{8}$ Since that time, there have been several studies validating their finding. ${ }^{7,9,10}$ The most current estimate states that there are approximately 15,000 intrathecal baclofen pumps in use throughout the world. ${ }^{10}$

Despite the noteworthy success of intrathecal baclofen therapy with regard to treatment of muscle spasticity, implantation of a baclofen pump device does not come without risks. Most commonly, the complications are the result of a problem with the catheter., ${ }^{1,3,9-11}$ Intrinsic pump malfunction appears to be a rare complication; there is only 1 reported case in the current literature. ${ }^{10}$ In this paper, we present the case of a 10-year-old boy who progressed to acute baclofen overdose on 2 separate occasions after baclofen pump refill by 2 different individuals. After careful interrogation of the pump by the parent company, the device was determined to have intrinsically failed.

\section{Case Report}

The patient is a 10 -year-old boy with spastic diplegia caused by cerebral palsy secondary to periventricular leukomalacia. His spasticity has been adequately treated with intrathecal baclofen since November of 2008.
In July of 2013, the patient presented to his neurologist's office for a routine refill of his Medtronic SynchroMed II baclofen pump. Using a standard refilling kit, a needle was inserted into the pump reservoir. The pump was refilled in the usual manner after entering through the pump's diaphragm with the provided needle. Four milliliters of baclofen was then removed from the pump and $40 \mathrm{ml}$ of $500 \mu \mathrm{g} / \mathrm{ml}$ baclofen was used to fill the pump to capacity. Shortly after the injection, the patient became progressively more unresponsive, became bradycardic, and required oxygen in the office. His pump rate was turned down to its lowest setting ( $3 \mu \mathrm{g} /$ day) by the neurologist. Emergency Medical Services was called to the office. The patient was intubated and stabilized and transported to our facility. On arrival, the decision was made to access both the reservoir and the catheter side port to remove any residual baclofen. On accessing the reservoir, $4 \mathrm{ml}$ of clear fluid was evacuated. Next, the catheter side port was entered using a 25 -gauge spinal needle. From this port, $3 \mathrm{ml}$ of clear fluid was removed. Supportive care was continued until the patient was extubated on hospital Day 2. On hospital Day 3, the decision was made to refill his pump due to symptoms of baclofen withdrawal.

The pump refill was performed using fluoroscopy to confirm needle placement. On confirmation of needle 
placement, the reservoir was filled with $40 \mathrm{ml}$ of $500 \mu \mathrm{g} /$ $\mathrm{ml}$ baclofen. The pump rate was continued at $3 \mu \mathrm{g} /$ day for the time being. However, once again, shortly after this procedure the patient became increasingly unresponsive, bradycardic, and hypotonic and had significant respiratory depression. Atropine and physostigmine were administered once again, with little response. Both the reservoir and catheter side port were accessed again. The reservoir was found to contain only $4 \mathrm{ml}$ of the previously instilled $40 \mathrm{ml}$ of baclofen. The catheter side port was entered and $17 \mathrm{ml}$ of clear fluid was removed as well. The patient was reintubated due to progressive respiratory symptoms.

After these 2 episodes the decision was made to replace the baclofen pump, following a family discussion of the risks and benefits of such an intervention. At that time, the pump was explanted and tested for leakage. No obvious leak was noted. The catheter was confirmed to be in continuity by using contrast dye and fluoroscopy. On hospital Day 6, the patient was extubated. Over the course of the day, his pump was reprogrammed 3 times at $50 \mu \mathrm{g} /$ day intervals. He tolerated each of these increases well until reaching a final dose of $150 \mu \mathrm{g} / \mathrm{day}$. His examination results remained stable and he showed no significant signs of baclofen toxicity or withdrawal. He was discharged home on hospital Day 9 with his examination findings approaching his neurological baseline. After 1 year of follow-up and multiple pump refills, no new incidents have occurred with the new pump.

The manufacturer interrogated the pump after explantation, and they noted that the pump acted as expected when tested at the maximum rate $(24,000 \mu \mathrm{l} /$ day $)$. When initially tested at a typical dose (300 $\mu \mathrm{l} /$ day), it functioned within normal limits. However, on a second testing at the same rate, the pump was found to deliver a much larger amount of baclofen. The pump was then tested a third time at this same rate for a longer duration, and it functioned within normal limits.

\section{Discussion}

Although intrathecal baclofen has numerous benefits in the appropriate patient population, the implantation of the pump and delivery of intrathecal baclofen does not come without risks. These risks can be the result of the drug itself, or due to the implanted pump and catheter. Typically, adverse effects of the drug itself are dose related in nature and are often easily corrected through dose adjustment. ${ }^{10}$ However, complications due to the catheter or pump itself remain a significant risk. In 2003, Gooch et al. ${ }^{5}$ reported that of 100 consecutive patients who received baclofen pumps, 24\% had a complication. Most commonly, this was noted to be a disconnection of the catheter from the pump itself. Also, in their study 3 patients were found to have pump failure, including disconnection of the catheter access port and tube compression failure. Other studies have reported a much higher rate of complications, including up to $40 \%$ of patients in 1 study. ${ }^{2}$ Although the true rate of complications may be disputable, it is obvious that implantation of intrathecal baclofen pumps does not come without risk of complications.

Withdrawal is also possible in the setting of pump complications, especially in the days after a significant baclo- fen overdose. The most common symptoms of withdrawal include rebound spasticity, tachycardia, hyperthermia, and seizures. Oftentimes, baclofen overdose or withdrawal in a patient with an intrathecal baclofen pump is due to malfunction of the pump system. As previously discussed, this is often due to difficulties with the catheter itself, most commonly discontinuity, kinking, or fracture of the catheter. ${ }^{1,67,10}$ In addition, displacement of the catheter can also lead to overdose. Most often, this involves the catheter being located in the subdural space. This should be suspected when a patient with a recently implanted pump is seeing little to no effect of the medication, despite significant increases in the delivery dose. This can be due to malpositioning at implantation or migration postimplantation. The pathophysiological mechanisms behind acute overdose in this setting involves baclofen building up in the subdural space and being released acutely into the subarachnoid space, oftentimes after a change in position., ${ }^{1,6,8}$

Pump failure, on the other hand, is a rare finding as a cause of baclofen overdose or withdrawal. In 2008 Medtronic, Inc., did recall a large number of SynchroMed pumps due to a deficient gas propellant. The propellant helps to advance the drug through the system and into the thecal sac. This deficiency can lead to serious malfunctions, causing over- or underdosage of baclofen. At that time, the company published information about the affected pumps on their website and listed the serial numbers.

There are very few reported cases in the literature describing pump failure. After a careful literature search, only 1 case was discovered. Sgouros et al. described pump failure as a cause of baclofen overdose in 2010. However, the pump described in their paper was tested by the company and found to have no intrinsic defect. Their diagnosis of pump failure was made by exclusion of other causes. ${ }^{9}$ More recently (on June 3, 2013), the FDA issued a Class I recall of pumps distributed between April 1999 and June 2013 due to the unintended delivery of drugs during the priming bolus procedure. During this procedure, patients may receive the drug unintentionally at a high rate of infusion in the CSF, followed by a period of reduced drug delivery after the priming bolus. This can result in a drug overdose or underdose, which can lead to serious medical illness such as respiratory depression, coma, or death. ${ }^{4} \mathrm{Of}$ note, the Class I recall did not result in any major change in the management of these cases, other than emphasizing the importance of monitoring of these types of symptoms in patients with pumps.

\section{Conclusions}

Our patient had 2 episodes of baclofen overdose secondary to potential intrinsic pump malfunction as described above. This is the only case currently reported in the literature with potential evidence of pump malfunction following testing provided by the manufacturer. This issue raises key questions on how a neurosurgeon should optimally deal with potentially life-threatening device failures and the role of the manufacturing company in light of such problems. Is it worthwhile for a third party to be responsible for reviewing medical device malfunctions? What is the threshold to consider replacement of medical devices? Who will be ultimately responsible to cover the 
cost of replacements? Although these topics are beyond the scope of this case report, it is worthwhile entertaining these questions.

\section{References}

1. Albright AL, Ferson SS: Intrathecal baclofen therapy in children. Neurosurg Focus 21(2):e3, 2006

2. Bardutzky J, Tronnier V, Schwab S, Meinck HM: Intrathecal baclofen for stiff-person syndrome: life-threatening intermittent catheter leakage. Neurology 60:1976-1978, 2003

3. Dalton C, Keenan E, Stevenson V: A novel cause of intrathecal baclofen overdosage: lessons to be learnt. Clin Rehabil 22:188-190, 2008

4. FDA: Medtronic SynchroMed II and SynchroMed EL Implantable Drug Infusion Pumps-Failure of Priming Bolus. (http://www.fda.gov/MedicalDevices/Safety/ ucm359119.htm) [Accessed April 8, 2015]

5. Gooch JL, Oberg WA, Grams B, Ward LA, Walker ML: Complications of intrathecal baclofen pumps in children. Pediatr Neurosurg 39:1-6, 2003

6. Haranhalli N, Anand D, Wisoff JH, Harter DH, Weiner HL, Blate M, et al: Intrathecal baclofen therapy: complication avoidance and management. Childs Nerv Syst 27:421-427, 2011

7. Lew SM, Psaty EL, Abbott R: An unusual cause of overdose after baclofen pump implantation: case report. Neurosurgery 56:E624, 2005
8. Penn RD, Kroin JS: Intrathecal baclofen alleviates spinal cord spasticity. Lancet 12:1078, 1984

9. Sgouros S, Charalambides C, Matsota P, Tsangaris I, Kostopanagiotou G: Malfunction of SynchroMed II baclofen pump delivers a near-lethal baclofen overdose. Pediatr Neurosurg 46: $62-65,2010$

10. Shirley KW, Kothare S, Piatt JH Jr, Adirim TA: Intrathecal baclofen overdose and withdrawal. Pediatr Emerg Care 22:258-261, 2006

11. Watve SV, Sivan M, Raza WA, Jamil FF: Management of acute overdose or withdrawal state in intrathecal baclofen therapy. Spinal Cord 50:107-111, 2012

\section{Author Contributions}

Conception and design: Rizk. Acquisition of data: Rizk. Analysis and interpretation of data: Rizk. Drafting the article: both authors. Critically revising the article: Rizk. Reviewed submitted version of manuscript: Rizk. Approved the final version of the manuscript on behalf of both authors: Rizk.

\section{Correspondence}

Elias Rizk, Department of Neurosurgery, Penn State Hershey Medical Center, EC 110, 30 Hope Dr., Hershey, PA 17033. email: erizk@hmc.psu.edu. 